\title{
Study on the Process-oriented Integrated Management of Construction Project
}

\author{
Yu Wu, Baoyin Zhang \& Bo Wang \\ College of Management, Tianjin University, Tianjin 300072, China
}

\begin{abstract}
In this article, we put forward the Process-Oriented Integrated Management of Construction Project (POIMCP). According to the process-oriented modeling theory, we establish the definition, character, objective and core task of POIMCP, bring forward corresponding management mode and establish a process-oriented integrated management model by means of the method of IDEF0.
\end{abstract}

Keywords: Construction project, Process-oriented, Concurrent engineering, Integrated management

\section{Introduction}

The construction project process management includes all necessary activities adopted to effectively control final output of project production, and the input of the process is decided by owners' demands to the construction project. Through a series of mutual associated or interactional activities, the final output of construction project process management is the construction project product which can fulfill owners' demands (Jiang, 2006). Because one construction project would experience many indispensable work stages from client contact, project application, feasible research analysis, project evaluation decision, project design, first-stage preparations (such as selections and purchases of main materials and equipments), organization and implementation, plan establishment, controls of project time limit quality and investment to finish, acceptance, delivery and use, so it is very necessary to implement scientific process-oriented integrated management research.

\section{The concept of POIMCP}

Considering the characters such as system, complexity, and dynamics of construction project and combining with actual demands, practices and cases of large of construction projects, aiming at construction project, especially for large-sized construction project, in this article, we put forward the concept of the process-oriented integrated management of construction project and define it as that based on systematical consideration to construction project, the process-oriented integrated management divides the all lifecycle of project into four stages including decision-making, design, construction and operation, and adopts the idea of concurrent engineering aiming at interior and exterior factors, activities and resources in different stages and on difference layers to establish the systematical model combining process system management with technology, and implements system control and harmony optimization of project management to realize the optimization among time limit, quality and cost for construction project (Zhu, 2002).

The process-oriented integrated management possesses following characters.

(1) Complexity. It is mainly to organically organize various parts of the construction project system from bottom to top and from top to bottom and form reasonable hiberarchy and function structure to make the system can adopt environment and exert optimal function, establish the uniform model to various stages of all lifecycle such as research, design and production, and various operation stages such as decision-making, plan and marketing, and implement the simulation and actual application of the system, which aim is to realize the harmony among enterprise, economy, resource and environment (Gu, 1998).

(2) The character of process. The process integration first will put forward the problems among technical design, arts and crafts design, frock design and production manufacturing, support neighbor courses each other and carry through the idea of concurrent engineering.

(3) The character of integration. Starting from the whole enterprise, exert the comprehensive integrated method combining with the innovation of management as viewed from the methodology, integrate modern information science, system science, management science, computer science, applied mathematics, corresponding theories and results and expert experiences of professional engineering technology together to instruct the comprehensive integration of the process system.

The essential of process-oriented construction project integrated management is to further eliminate various redundancies and non-increment sub-processes (activities) and all obstacles influencing the process efficiency induced by artificial factors and resources after finishing information integration and harmony among various 
courses of construction project to optimize the total process of the construction process, which is represented in that after putting forward the conflicts among schedule, cost and resource of construction project, the upper courses consider the lower courses, and neighbor courses support each other and carry though the concept of concurrent engineering to implement the management of the whole construction project.

The core task of process-oriented construction project integrated management is to optimize the objective structure and implement the comprehensive plan and control for schedule, cost and resource. In the integrated management control system of construction project, first put forward many plans about division and optimization of project process and stage, implement technical and economical analysis and realize the comprehensive optimization of plan (control) system, then implement relative harmony works according to the situation of every stage, and these project construction activities must work under the control of integrated control system. Starting from the system control theory, this article systematically analyzes the project process control, makes the implementation of system objective ensure the implementation of whole system objective, and various objectives of subsystems are integrated into the complete total subjective system to enhance the management efficiency and exert the whole function.

\section{The introduction of the POIMCP mode}

Because the project management mode of construction project is selected by the owner according to the concrete situation of the project, the advantage analysis to different integrated degrees of different project management modes and the project management mode with high integrated degree are mainly implemented from the view of owner's benefits. However, more proper project management mode can realize the benefits of the whole construction project and make various participators of the project win together. Considering the characters such as complexity, system and all lifecycle of the construction project and combining with the character of the process-oriented integrated management, this article puts forward the process-oriented integrated management mode based on the concept of concurrent engineering.

The concurrent engineering is the systematic method of product and its production support process concurrent design, and it is a sort of systematic work mode to implement concurrent and integrated design for the product (the concept of the product means all research objectives but not only certain special one product of mechanism or other aspects) and its relative process (Ma, 2003). The concurrent engineering possesses the characters of concurrent, constraint, coordination and consistent, and its objective is to enhance quality, reduce cost project development cycle and project accomplishment time. The concurrent engineering emphasizes that various personnel organizationally cooperate with works and comprehensively design products and clients' demands in the process-oriented construction project. The implementation frame of concurrent engineering includes the people-oriented organizational management frame, computer assistant tool frame and method frame and the integration of other series of frame.

The process-oriented integrated management mode is to exert the ideas of system, management integration and process integration, take the various stages of construction project lifecycle as an organic entity, utilize the dynamic control method and the concept of concurrent engineering starting from the view of three objective controls of construction project, make various participation methods of construction project grasp this point when implementing its function of management, analyze, adjust and perfect the initial project of construction project and the influence of every stage to cost, schedule and quality. The standards of analysis, evaluation, decision and implementation to any project is to complete the construction of project with the shortest work term and high quality in the stated investment budget range (Zhao, 2004).

The organization of the process-oriented integrated management mode is to require respectively selecting one or two principals to compose project leading core of construction representations from main participators of contractors in the process of construction process, building the decision team system of construction project process integrated management information system, timely collect and feed back the information of project decision, project design, project construction, project acceptance and project operation through the construction project process integrated management information system, harmonize and control all participators form cooperation and trust in various stages, make the lower processes support the upper processes, definitude the concrete responsibilities and implementation plans of project construction and ensure the realization of project objective. The Figure 1 is the concrete implementation mode of the process-oriented construction project integrated management.

The process-oriented integrated management mode possesses following characters.

(1) Simple organizational institution, high work efficiency, and the owner can participate in the preparation, design, and construction of the whole construction project and is in the dominant status.

(2) Adopting the method of concurrent operation, timely getting the information feedback and the support channel between the upper and lower processes and the term of construction is reduced. 
(3) Emphasizing the cooperative operation from design to the construction and the harmony among various concurrent projects or concurrent works.

(4) Establishing the integrated management information system of construction project, implementing vertical flow and feedback of information current to the plan and control of various concurrent projects in time, and implementing transverse communication of various concurrent projects to realize resource sharing and mutual compensations.

(5) Establishing new cooperative relationship among owner, project manager, contractor and supplier, enhancing management benefit reducing the cost of construction.

\section{Using IDEF0 to establish the POIMCP model}

As a complex system, the opening of construction project fully increases unforeseen factors. To establish an integrated system, we must fully know the information and process in the project, and the range and information requirements covered by the whole process.

IDEF (ICAM Definition Method) is a set of modeling method to describe the operation in the interior of the enterprise, which is developed as a set of system analysis and design method based on the structured analysis method of US air force ICAM C Integrated Computer-aided Manufacturing project, and it is broadly applied in the software development after reconstruction only exerting in the manufacturing. From IDEF0 to IDEF14 (including IDEF1X), there are 16 sets of method, and every set of method is to obtain special type information through the modeling program. The IDEF method is to establish the image expression and analysis system module of various systems, found the optimal edition of system, and help the conversion among different systems.

Therefore, the IDEF0 functional modeling method is used to establish model to the construction process of construction project, implement recursive hiberarchy decomposing from various stages of the whole project to the sub-stage and sub-process, establish mutual association and information communication route among processes, which can clearly understand the whole construction implementation process of the whole construction project.

As seen in Figure 2, the process-oriented construction project integrated management model divides the whole project lifecycle into four functional stages, i.e. project decision-making, project design, project construction and project operation, and the output of every functional stage is the control condition or input of next functional module. The inputs of whole project process are existing resources which include the project entity and relative historical material, and the control conditions includes the construction units and relative laws and regulations in the implementation process of various functions, and relative establishments and equipments, human resources and environments are took as the mechanism of the whole model, and the final output results are products or services, i.e. the intention that establishes this project. In the process of project design and construction, the unqualified designs and projects which can not achieve the anticipative demands should be redesigned, reconstructed, and controlled circularly until achieving the scheduled standard to export to next stage.

Where, to the project demand of construction units and relative laws and regulations in the implementation process of various functions as control conditions, the relative establishments and equipments, human resource and environment as mechanism conditions, and stage results occurred in various sub-stages as output conditions, we should implement comprehensive information treatment, timely feedback, effective guidance and advancement through the information integrated system of construction project.

Various participators of process-oriented integrated management should participate in the decision-making of project, offer advices and opinions for the implementation of the project, and ensure the system character of project decision and the feasibility of the project objective. The design and implementation of project are integrated in single dynamical activity, which makes the design or construction mode not only become into a sort of purchase mode, but a sort of control system of project management. The process-oriented integrated management emphasizes the influences of design stage to the project result, and emphasizes owners' status and function in the whole process of project implementation.

The process-oriented integrated management changed in the aspects of organization and harmony (Adnane, 2004). More and more problems about superposition induced in various participators' participations and implementation in the project implementation process can make various participators who were only responsible for one stage or one work in the project lifecycle have opportunities and impetus to participate in other works, which improves various participators' communication and cooperation, and more detailed decision function division, definitude various decision functions such as harmony, design and plan in the dynamic complex project, so the most proper participator can charge the decision, and more and quicker information communication and feedback can be realized among various decision functions, and the detailed degree and reliability of design, plan or implementation follow can be enhanced. 


\section{Conclusions}

According to the up-to-the-minute researches of modern project management, in this article, we put forward the idea of process-oriented integrated management of construction project which core method is to divide the management process of construction project into different relatively independent stages, and we also adopt the ides of concurrent engineering according to the process-oriented modeling theory and establish the definition, character, objective and core task of the process-oriented integrated management of construction project, and bring forward corresponding management mode and adopt the method of IDEF0 to establish a process-oriented integrated management model. In the whole management process of construction project, we should always surround the special construction project control system composed by three systems including schedule, cost and resource, and take the process-oriented integrated management as a function work of project management to implement through the whole process of construction project management.

\section{References}

Adnane Belot \& Clothilde Gauvreau. (2004). Factors Influencing Project Success: the Impact of Human Resource Management. International Journal of Project Management. No.22.

Gu, Peiliang. (1998). System Analysis and Harmony. Tianjin: Tianjin University Press.

Jiang, Wuju. (2006). Project Process Management and Implementation. Inner Mongolia Science \& Technology and Economy. No.11.

Ma, Shixiao, Zhang, Guozhong \& Xu, Wanhong. (2003). On Concurrent Engineering and Its Applying Cases. Machinery Design \& Manufacture. No.4.

Zhao, Likun \& Chen, Liwen. (2004). Research on Project Management Pattern of Synthetical Integration. Construction Economy. No.1.

Zhu, Xunjie. (2002). Polemic Relation between the Three Goals of Construction Project. Construction Management Modernization. No.11. 


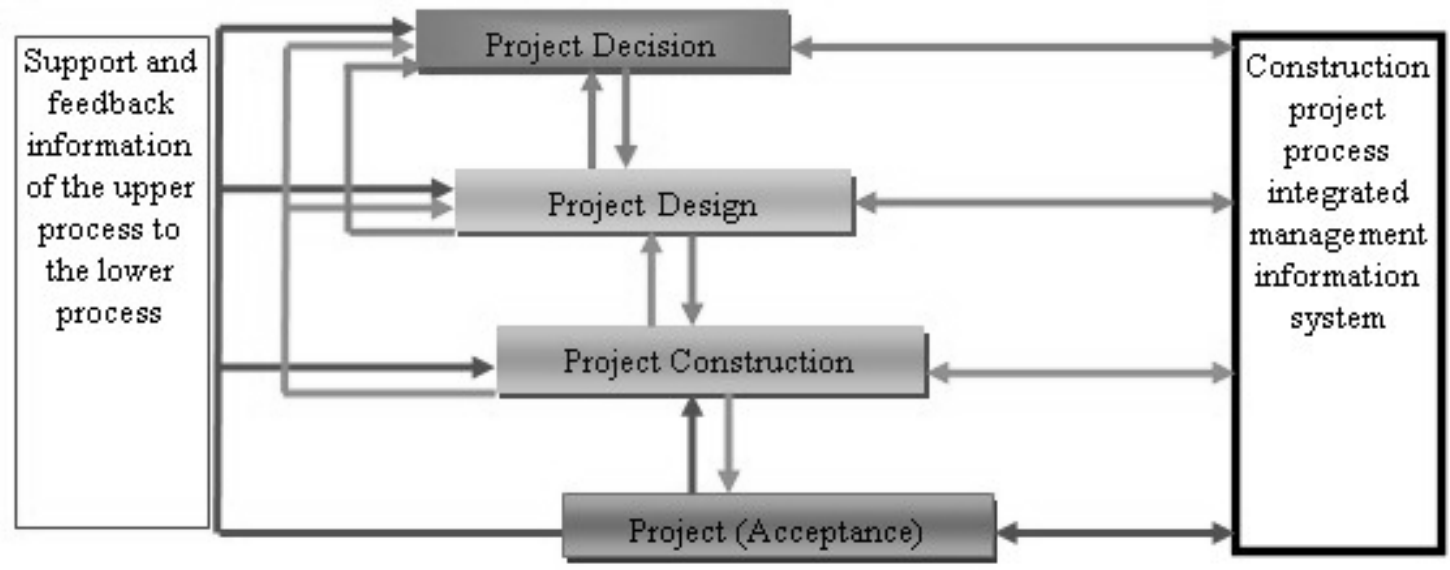

Figure 1. The Process-oriented Construction Project Integrated Management Mode

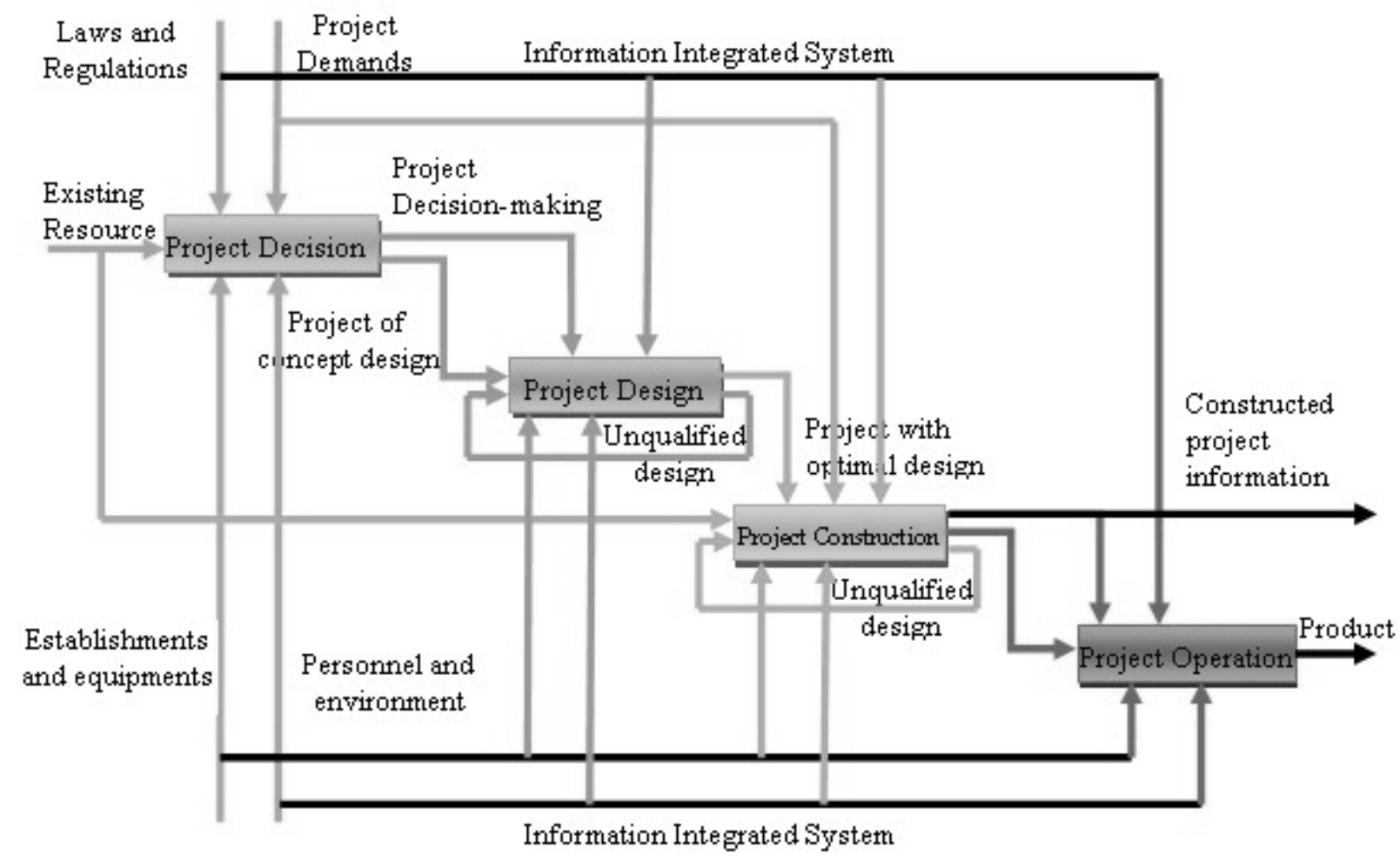

Figure 2. The Process-oriented Construction Project Integrated Management Model 